\title{
Development and validation of a quasi-dimensional model for methanol and ethanol fueled SI engines
}

\author{
J. Vancoillie, L. Sileghem, S. Verhelst \\ Department of Flow, Heat and Combustion Mechanics, Ghent University \\ Sint-Pietersnieuwstraat 41 B-9000 Gent, Belgium
}

Abstract

Methanol and ethanol are promising alternative SI engine fuels. Engine simulation tools could help to unlock the full potential of these fuels. Previous work by the current authors has focused on building submodels to predict the gas dynamics, combustion and knock occurrence in alcohol engines. Here, these building blocks are implemented in a quasi-dimensional engine simulation code, which is subsequently validated against measurements on two engines for various working conditions. The power cycle predictions for varying mixture composition are significantly improved by the introduction of new laminar burning velocity correlations. A comparison of turbulent combustion models indicates that models including thermodiffusive properties perform slightly better than simpler formulations. Finally, a preliminary evaluation of a new knock prediction model for methanol engines confirms useful results can be obtained for quantities relevant to knock. The largest inaccuracies occur for varying equivalence ratios. Including the effects of methanol on evaporation cooling and wall heat transfer might resolve this. The higher heat of vaporization relative to gasoline also required the inclusion of fuel puddling dynamics for a correct prediction of the volumetric efficiency by the breathing cycle model.

25 Keywords: methanol, ethanol, spark-ignition engine, thermodynamic, modeling, knock

\footnotetext{
${ }^{*}$ Corresponding author. Tel.: +32(0)92643306; Fax: +32(0)92643590

Email address: sebastian.verhelst@ugent.be (S. Verhelst)
} 


\section{Introduction}

\subsection{Light alcohols as SI engine fuels}

Sustainable light alcohols such as methanol and ethanol are interesting alternative fuels, pure or as blend component for spark-ignition (SI) engines $[1,2]$ and homogeneous charge compression ignition (HCCI) engines [3, 4]. They offer the potential of $\mathrm{CO}_{2}$ neutral transport and increased energy security, while ameliorating engine performance and efficiency compared to fossil fuels thanks to a number of interesting properties $[5,6]$. The most significant interesting properties of light alcohols include:

- High heat of vaporization, which causes considerable charge cooling as the injected fuel evaporates.

- Elevated knock resistance, which allows to apply higher compression ratios $(\mathrm{CR})$, optimal spark timing and aggressive downsizing.

- High flame speeds, enabling qualitative load control using mixture richness or varying amounts of exhaust gas recirculation (EGR) [1].

The potential of neat light alcohol fuels (methanol and ethanol) has been demonstrated experimentally in both dedicated and flex-fuel alcohol engines [1]. Today, however, costly experimental tests are increasingly replaced by cheap system simulations of the engine. With current trends like alternative fuels, downsizing, EGR, multiple spark plugs per cylinder, etc. it is indeed no longer possible for an R\&D engineer to intuitively grasp how these factors will affect the engine operation. The employed engine models are obviously required to reproduce any fuel specific effects on the combustion process.

50 Quasi-dimensional (QD) engine simulation codes are well suited to evaluate existing engines, perform parameter studies and predict optimum engine settings without resorting to complex multidimensional models [7]. The governing equations for such models are based on conservation of mass and energy. A two-zone formulation separates the burned from the unburned gases by an infinitely thin, spherically propagating flame front. At Ghent University, a QD code for the power cycle of hydrogen fueled engines has been developed and validated during earlier work (GUEST: Ghent University Engine Simulation Tool) [8]. The current work aims to extend this code to light alcohol fuels (i.e. methanol and ethanol) and to add models predicting the gas dynamics and knock onset in engines running on these fuels. 


\subsection{Quasi-dimensional engine modeling}

Throughout the years, several authors have published QD simulation results for alcohol engines. In the early 90's Mohanan and Babu simulated the performance and emissions of different engine configurations fueled with gasoline-methanol blends [9] using a two-zone quasi-dimensional model. The authors report a lack of data for the laminar burning velocity of methanol and calculated this quantity using chemical kinetics results of Westbrook [10].

Later Brown et al. used the entrainment combustion model described Appendix A to compare the combustion of iso-octane and methanol in a single-cylinder research engine [11]. The turbulent burning velocity was calculated using the Damköhler model: $u_{t}=u_{l}+u^{\prime}$. The laminar burning velocity of methanol was calculated using a correlation by Gibbs and Calcote [12], combined with the temperature and pressure trends predicted by developed for gasoline combustion [14]. They note that a correct calculation of the evaporation cooling by methanol is needed to predict the volumetric efficiency. Also, the employed laminar burning velocity correlation resulted in poor results for rich mixtures. Pourkhesalian et al. [15] came to the same conclusions using a similar model for engines running on neat methanol and ethanol.

Recently, Bougrine et al. [16] used their reduced Coherent Flame Model (see Appendix A) to predict the performance, emissions and knock occurrence in a directly injected single cylinder engine fueled with stoichiometric gasoline-ethanol blends up to 30 vol\% ethanol. They used Gülder's laminar burning velocity correlation [17], but mentioned the lack of a correct expression for the pressure sensitivity of $u_{l}$ for these blends. The influence of residual gases was implemented using an expression developed for gasoline. Knock was predicted using the model of Douaud and Eyzat developed for primary reference fuels [18]. The authors reported that indicated mean effective pressure (IMEP) was predicted within 1 bar for $70 \%$ of the operating points, which were all at stoichiometric conditions. Knock-limited spark advance was predicted within $2^{\circ}$ crank angle.

As may be clear from the previous discussion, most simulation codes for alcohol engines resort to models developed for hydrocarbon fuels, although in reality changes can be expected in the relevant mechanisms for combustion, emission formation and knock. With regard to combustion, none of the published simulation models employs a laminar burning velocity correlation that 
correctly accounts for changes in pressure, temperature and mixture composition. There is a lack of knock models developed specifically for alcohol fuels. Furthermore, engine performance, emission formation and knock occurrence are heavily influenced by the effects of evaporation cooling. Therefore, the dynamics of fuel impingement and puddling must be considered in detail. This will be returned upon in Sections 3.2, 5 and 6 .

\section{Simulation program}

\subsection{Framework and assumptions}

The focus of this paper is the validation of the turbulent combustion models and knock prediction model for engine operation on neat methanol and ethanol. Also, the in-house GUEST code was coupled to a commercial gas dynamics simulation tool, to enable simulation of the entire engine cycle (GT-Power [19]).

The current two-zone QD power cycle model was derived using several standard assumptions, discussed in $[8,7]$. The equations for the rate of change of the cylinder pressure $\mathrm{d} p / \mathrm{d} \theta$, burned and unburned temperatures, $\mathrm{d} T_{b} / \mathrm{d} \theta$ and $\mathrm{d} T_{u} / \mathrm{d} \theta$, are derived from conservation of energy. Additionally, a number of models and assumptions are necessary to close these equations. These are discussed in Appendix A and earlier publications [20].

\subsection{Turbulent combustion model}

A turbulent entrainment velocity $u_{t e}$ is needed for closure of Equation A.2. A number of $u_{t e}$ models were selected through comparison against measurements of the turbulent burning velocity of methanol- and ethanolair obtained during spherical explosions in a constant volume bomb [21, 22]. The models were implemented as summarized below. A full description of the different models can be found in the original references or in [21].

- Damköhler [23]:

$$
u_{t}=C_{2} u^{\prime}+u_{n}
$$

- Gülder [24]:

$$
u_{t}=0.6 C_{2} u^{\prime 0.5} u_{n}^{0.5} R e_{t}^{0.25}+u_{n}
$$

- Bradley KaLe [25]:

$$
u_{t}=0.88 C_{2} u^{\prime}(\text { KaLe })^{-0.3}+u_{n}
$$


- Zimont [26, 27]:

$$
u_{t}=C_{2} u^{\prime} D a^{1 / 4}+u_{n}
$$

- Dinkelacker [28]:

$$
u_{t}=u_{n}+\frac{0.46 C_{2} \cdot u_{n}}{L e} R e_{t}^{0.25}\left(\frac{u^{\prime}}{u_{n}}\right)^{0.3}\left(\frac{p}{p_{0}}\right)^{0.2}
$$

- Richard et al. [29] have recently reduced their 3D Coherent Flame Model (CFM) to a formulation that is compatible with QD engine modeling. The model formulation is summarized in Appendix A.

$C_{2}$ is a calibration constant, $u_{n}$ is the stretched laminar burning velocity, $K a$ is the Karlovitz stretch factor [25], Le is the Lewis number and $D a$ is the

Damköhler number which is calculated using a laminar flame thickness based on the kinematic viscosity $\left(\delta_{l}=\nu_{u} / u_{l}\right)$. Alternatively, the flame thickness can be more precisely calculated using the $\delta_{l}$ correlations developed by the current authors $[20,21]$. The best results were obtained without the use of a stretch model, i.e. $u_{n}=u_{l}$.

\subsection{Laminar burning velocity correlation}

Turbulent burning velocity models need (stretched) laminar burning velocity data of the air/fuel/residuals mixture at the instantaneous pressure and temperature. As of today, there are insufficient data on stretch-free burning velocities at engine conditions, for any fuel. Stretch and instabilities hamper the experimental determination of stretch-free data at higher (engine-like) pressures [30].

The current authors have worked on the laminar burning velocity of methanol and ethanol mixtures, compiling data from the literature [31] and looking at numerical [31] as well as experimental [5, 32, 33] means to determine a suitable laminar burning velocity correlation. Laminar burning velocity correlations for methanol and ethanol have been determined based on chemical kinetics calculations [31]. These correlations have been extensively validated against measurements obtained on two different fundamental combustion research setups $[5,32,33]$.

155 Figure 1 shows that, compared to the older correlations of Metghalchi \& Keck and Gülder, the methanol $u_{l}$ correlation developed by the current authors places the peak laminar burning velocity at a richer equivalence 
ratio and predicts a less steep decrease in $u_{l}$ for rich mixtures. The residual gas correction term of Rhodes and Keck, developed for indolene/air/diluents mixtures, predicts a steeper drop in burning velocity in terms of diluents ratio than the other correlations. Similar observations can be made for the $u_{l}$ correlations of ethanol (not shown here).

\subsection{Knock model}

Alcohol fuels have a higher knock resistance than gasoline for a variety of reasons, including autoignition chemistry and intense vaporization cooling [34].

The current authors have developed a knock prediction model to accurately reproduce the effect of varying engine designs and operation conditions (load, compression ratio, $\phi$ and EGR\%) on knock tendency in methanol engines [34]. A similar model was developed for ethanol by Yates et al. [35].

The employed modeling approach is based on the conservation of ignition delay principle expounded by Livengood and $\mathrm{Wu}$ [36]. This principle is analytically expressed by the knock integral reaching unity.

$$
\int_{t_{I V C}}^{t_{K O}} \frac{\mathrm{d} t}{\tau(t)}=1
$$

Where $t_{I V C}$ and $t_{K O}$ are the time at intake valve closure and knock onset respectively, and $\tau(t)$ is the instantaneous autoignition delay time.

The autoignition delay time $\tau$ (in $\mathrm{s}$ ) at instantaneous cylinder pressure ( $p$ [bar $])$, unburned mixture temperature $(T[\mathrm{~K}])$ and composition is typically given by an Arrhenius expression representing the rate limiting step of autoignition.

$$
\tau=A p^{n} e^{\frac{B}{T}}
$$

Where $A, n$ and $B$ are parameters depending on the mixture composition (fuel, $\phi$, residual gas ratio). A $\tau$ correlation was constructed for methanol based on a library of autoignition delay times computed using the methanol oxidation mechanism of Li et al. [37]. This is the same mechanism used to develop a laminar burning velocity correlation for methanol. This $\tau$ correlation has been validated using various published experimental datasets for the autoignition delay time of methanol [34]. 


\section{Model validation}

\subsection{Engine measurements}

To validate the combustion and knock models' predictive capabilities, a

series of measurements were done on a port-fuel injected CFR engine and a single cylinder Audi research engine. Both engines and the employed measurement equipment have been discussed elsewhere [38, 39, 21]. The main characteristics of the engines are summarized in Table 1. As discussed in [34], knock occurrence and intensity were detected based on the measured pressure oscillations using the algorithm of Worret et al. [40].

The measurements on the CFR engine comprise variable fuel/air equivalence ratio $\phi$, ignition timing (IT), compression ratio (CR) and throttle position (TP). Those on the Audi engine considered varying rpm, ignition timing, $\phi$ and EGR\% (see Tables A.3-A.5 in Appendix A). In order to allow distinction of the individual effects of these parameters, without resorting to a lot of one factor at a time sweeps, the experimental conditions have been chosen in such a way that Response Surface Methods can be applied to analyze the results [41]. This way, the resulting quantities of interest (e.g. IMEP, ignition delay) can be fit as a function of the individual parameters.

\subsection{Model setup and calibration}

As the main focus of the current work was to evaluate combustion models, the employed engine model is limited to the closed part of the engine cycle (IVC to EVO). The initial conditions for mass fractions of air and fuel, the mean temperature and pressure at IVC are taken from the measurements. The residual gases (from the previous engine cycle) are estimated using a gas dynamics model of the entire intake and exhaust geometry constructed using the commercial engine simulation software GT-Power [19] in combination with measured valve discharge coefficients (see section 6).

In the simulations used to evaluate the knock model, the measured burn rate was used instead of a prediction by a combustion model. This way the knock prediction model could be tested independently from the turbulent combustion model. Note that the burning velocity of alcohols can be $50 \%$ faster than that of gasoline, which contributes to the increased knock resistance of alcohol fuels [1]. Additionally, there were some specific model features relevant to the temperature sensitivity of autoignition kinetics: 
- The intake mixture was completely evaporated (m)ethanol-air with the measured equivalence ratio. The (m)ethanol was assumed to have vaporized by absorbing heat from the structure, not from the mixture. Note that this is a rather strong assumption given (m)ethanol's high heat of vaporization, as further explained in Section 6. However, this is necessary because of a current lack of data.

- Measured cylinder wall temperatures were applied to the cylinder wall, head and piston surfaces [42].

- The heat transfer was calculated using the model of Woschni and the unburned mixture was treated as a single zone.

- The applied burn rates were those resulting from a reverse heat release rate analysis of the measured pressure trace that best corresponded to the average cylinder pressure trace (average of 100 cycles).

The calibration fixes the coefficients for the heat transfer model, the flame development model $\left(C_{1}\right)$, the turbulent burning velocity model $\left(C_{2}, C_{3}\right)$ and the knock model. For each model, the code has been calibrated at the condition in the middle of the explored parameter space. The calibration constants are left constant for the other conditions. Details regarding the calibration can be found in Appendix A.

\section{Power cycle model}

\subsection{Sensitivity analysis}

The input data for a closed cycle simulation are always subject to some uncertainty. Some parameters, such as VE and external EGR\% can be measured experimentally, with some associated uncertainty. Others, such as internal EGR\%, $\Lambda$ and $u^{\prime}$ are difficult to measure and must be estimated from a gas dynamics simulation.

In order to understand to what extent simulation inaccuracies are the result of either inherent input uncertainties or wrong representation of alcoholspecific physical phenomena, an analysis was conducted to determine how sensitive the results of the power cycle code were to small changes in the input parameters. The following parameters have been investigated:

- Position and volume of the initial flame kernel 
- Position of the flame center: Movement towards the center of the combustion chamber has been reported during experiments in optical engines [43]. Two scenarios have been investigated: no movement (base conditions) and almost immediate movement.

- Compression ratio and head dome height: these geometrical parameters are usually well known for production engines but for the research engines used here, there is some uncertainty.

- Volumetric efficiency: both measurement and estimation from gas dynamics induce some error.

- $u_{l}$ and EGR\%: because $u_{l}$ correlations have not been validated at engine-like conditions, some divergence is to be expected. The large uncertainty on estimated internal and measured external EGR\% will influence $u_{l}$ and in-cylinder mass significantly.

- Heat transfer: for most engines, there is no direct measure of the wall heat transfer rate and a multiplier is used to calibrate the heat transfer at one operating point. Demuynck [42] illustrated that for methanol large variations in $\phi$ can lead to under/overestimations of the heat transfer rate by the Woschni model [44] of up to $50 \%$.

The sensitivity analysis has been performed using a closed cycle model of the Audi engine, with the methanol $u_{l}$ correlation developed by the current authors [31] and the $u_{t e}$ model of Zimont. The different parameters have been varied in a range that represents a reasonable worst case estimation of the uncertainty on its value based on the experimental error analysis and the sensitivity analysis for the gas dynamics simulation discussed in [21] (see Table 2). The results are presented as averaged values throughout the considered speed range of 1500-3500 rpm, with an error flag indicating the standard deviation.

Figure 2 shows the average percentual changes in ignition delay (0-2\% burned) and main combustion duration (10-90\% burned) caused by variation in the input parameters. The average base values are $12{ }^{\circ} \mathrm{ca}$ and $19{ }^{\circ} \mathrm{ca}$ respectively. Figure 3 shows the associated absolute changes in peak cylinder pressure. The average base value is 53 bar.

285 Figure 2 illustrates that uncertainties that lead to an increase in laminar $\left(u_{l}\right.$ and EGR\%) and turbulent burning velocity (rms turbulent velocity $u^{\prime}$ 
and integral length scale $\Lambda$ ) generally reduce $0-2 \%$ burn time. Although $\Lambda$ is directly proportional to the burn-up time constant $\tau_{b}$, an increase in its value apparently reduces $0-2 \%$ burn time. This is due to the $\Lambda^{1 / 4}$ dependence in the $u_{t}$ expression of Zimont (Eq. 4). Obviously, a larger initial flame kernel will significantly speed up the early combustion. The main combustion duration is significantly affected by uncertainties changing $u_{t e}$. Spark plug position and movement, however, have an even larger effect, since these factors determine if the flame front can freely develop or is truncated by the combustion chamber walls. A more eccentric spark plug will lead to slower 10-90\% burn time.

An uncertainty leading to faster combustion will generally lead to an earlier crank angle of maximum pressure, while the maximum pressure itself is seen to remain relatively unaffected (Figure 3). Notable exceptions are the influence of flame center and laminar burning velocity at the lowest rpm. The uncertainty in heat transfer rate has the largest influence on peak pressure, while the volumetric efficiency and EGR\% also lead to significant changes since these determine the amount of cylinder mass. The effect of compression ratio error is rather limited.

Figure 4 illustrates that faster combustion is associated with higher peak unburned gas temperatures. Overestimations of volumetric efficiency and EGR\% have a large effect as the temperature at IVC is calculated from the ideal gas law, so more in-cylinder mass at the same initial pressure leads to lower temperatures. The uncertainty on heat transfer obviously has a defining influence, which is important when considering $\mathrm{NO}_{\mathrm{x}}$ and knock prediction in engines.

The results above confirm the importance of the laminar burning velocity correlation and the estimation of volumetric efficiency and residual gas fraction from a breathing cycle simulation. An obvious weak spot of the current modeling methodology is the absence of data for in-cylinder turbulence, bulk flow and movement of the flame center. Model accuracy could benefit from a study of these factors in an optically accessible engine.

\subsection{Validation on the CFR engine}

A first validation of the power cycle routines was performed using the RSM measurement sets obtained on the CFR engine while running on neat methanol and ethanol. Earlier work by the current authors demonstrated that the new laminar burning velocity for methanol leads to better representation of the effect of varying mixture composition [20]. In the following, the 
predictive performance of the correlation for ethanol is evaluated. Addition325 ally several turbulent burning velocity models are compared for methanol and ethanol operation with variations in compression ratio $(\mathrm{CR})$, ignition timing (IT), throttle position (TP) and fuel-air equivalence ratio $(\phi)$.

In what follows the experimental and simulation results are synthesized into graphs showing ignition delay ( $0-2 \%$ burn time) and main combustion duration (10-90\% burn time). These graphs show sectional views at the center point of the response surfaces fitted to the experimental and simulation results.

For the methanol simulations in this section, the new laminar burning velocity correlation was used [31]. The calibration constants for the six turTable A.7. For ethanol, the new correlation is used, next to the $u_{l}$ correlation of Gülder [17], which it is often used in published modeling work $[45,16]$. The calibration constants for the various $u_{t e}$ models for the ethanol simulations are summarized in Appendix A.4.

340 The results for varying $\mathrm{CR}$ are shown in Figure 5. The ignition delay slightly reduces at higher compression ratios. This is reproduced by the model due to a reduced burn-up time constant $\tau_{b}$ at higher CR. The experimental 10-90\% burn time slightly decreases with rising CR, which is not reproduced by the model. A possible explanation is that the effect of compression ratio on turbulence is not well captured and the flame area reduction due to more flame-wall contact is overestimated by the model.

For methanol, the results for varying CR and spark timing are very similar for most turbulent combustion models (see Fig. 5 and 6). A notable exception is the Dinkelacker model, where the inclusion of an explicit pres350 sure dependent term in the $u_{t e}$ expression leads to a reduction of the main combustion duration at high pressure conditions (high CR, early spark timing). For ethanol, the same trends are observed as with methanol operation. The errors in 10-90\% burn time are most distinct when the $u_{l}$ correlation of Gülder is used (in combination with the Zimont $u_{t}$ model). This indicates that this correlation produces an incorrect trend for varying temperatures.

The ignition delay is barely influenced by spark timing (see Fig. 6). One might expect a slight reduction at more retarded spark timing due to the higher $u_{l}$ (higher $T$ ). However, in the models this effect is counteracted by the reduction in $u^{\prime}$ and corresponding increase in burn-up time constant $\tau_{b}$.

360 The reduction in $u^{\prime}$ at more retarded ignition timing is also responsible for the increase in 10-90\% burn time, reflected in the measurements. These ef- 
fects are well reproduced by all turbulent combustion models. The results for ethanol confirm the deviating behavior of the Gülder $u_{l}$ correlation. All models using the new laminar burning velocity correlation correctly reproduce the trends for ignition delay and 10-90\% burn time.

Differences between the turbulent burning velocity models begin to appear when simulating changes in mixture composition. Figure 7 displays the results for varying throttle position. A more closed throttle reduces the laminar burning velocity, leading to an increase in ignition delay, which is well predicted by all the models. However, the increased residual gas content, see Fig. 8, also lengthens the main combustion duration and the ability to predict this effect varies between models.

The models of Zimont, Gülder and Bradley follow the trend observed in the measurements, while the Damköhler model displays a low sensitivity to the increased EGR\%. As explained by Verhelst [46], the Damköhler model does not contain the laminar burning velocity nor mixture properties in the turbulent contribution to $u_{t e}$. This explains why this model is less sensitive to changes in mixture composition.

The Dinkelacker model overpredicts the effect of throttle position due to a lower pressure (and thus lower $u_{t e}$, see Eq. 5) at reduced loads. The vast errors induced by the CFM model are probably caused by the direct dependence of the flame wrinkling efficiency function $\Gamma$ to the laminar flame thickness $\delta_{l}$, which steeply increases with reduced pressure (more closed throttle).

For methanol, the results for varying equivalence ratio in Figure 9 confirm the distinction between the Damköhler model and the rest of the models. Compared to those models, the predicted $0-2 \%$ and $10-90 \%$ burn times are less dependent on the changes in $u_{l}$ associated with the equivalence ratio.

All models overpredict the ignition delay for rich mixtures. This is possibly due to cellular instabilities in rich, laminar flames (negative Markstein numbers), which are not accounted for in the models. The explicit inclusion of the Lewis number $L e$ in the $u_{t e}$ expression makes for slightly better predictions for ignition delay by the KaLe and Dinkelacker models.

The influence of $\phi$ on the main combustion duration is best predicted by the Damköhler model. The model of Dinkelacker underestimates the combustion duration for rich mixtures and vice versa for lean mixtures, probably due to the strong Le dependence. The CFM model also produces poor results for rich mixtures.

For ethanol, employing the $u_{l}$ correlation of Gülder causes vast overpredictions of the ignition delay and main combustion duration for rich and lean 
mixtures.

For ignition delay, there is a slight underprediction for most $u_{t}$ expressions, except that of Dinkelacker, thanks to its direct pressure dependence (lean mixtures produce lower peak pressures). The same pressure dependence, in combination with the effect of $L e$, is the reason why the Dinkelacker model markedly overestimates the effects of varying $\phi$ on the main combustion duration.

\subsection{Validation on the Audi engine}

To evaluate whether the different turbulent combustion models can recover the correct behavior with the rms turbulent velocity $u^{\prime}$, residual ratio and engine geometry, experiments with varying engine speed $\left(\sim u^{\prime}\right)$ and external EGR\% ( residual ratio) have been performed on the Audi engine. Calibration constants for the various turbulent combustion models are listed in Appendix A.4.

Results for varying engine speed are plotted in Figure 10. For this engine model, the default $k-\epsilon$ turbulence model of GT-Power was used in combination with the boundary conditions for $u^{\prime}$ and $\Lambda$ obtained from a gas dynamics simulation. Figure 10 indicates that the Damköhler model better reproduces trends with $u^{\prime}$. The $u_{t e}$ predicted by this model is more dependent on $u^{\prime}$ compared to the other formulations considered here (Eq. 1, $u_{t e} \sim u^{\prime}$ ). The Dinkelacker model performs worst since it is the least sensitive to changes in $u^{\prime}$ (Eq. 5, $\left.u_{t e} \sim R e^{0.25} u^{\prime 0.3} \sim u^{\prime 0.55}\right)$.

Then again, with the current research equipment it is impossible to verify whether the values for $u^{\prime}$ and $\Lambda$ predicted by the employed turbulence model correctly reflect the real evolution with engine speed. Because the default turbulent combustion model in GT-Power is of the Damköhler type, the turbulence routines are possibly tuned for best performance with this model. Additionally, the influence of bulk flow motion (e.g. swirl, tumble) has been neglected.

The results for varying ignition timing and load were very similar to those obtained on the CFR engine and are not repeated here. For the effect of $\phi$, the conclusions are similar as in the previous section (Figure 11). There is a slight overestimation of the $0-2 \%$ and $10-90 \%$ burn times for the richest mixtures by all models, except that of Dinkelacker, due to its strong dependence on Le. This strong dependence also causes overestimations of the main combustion duration for lean mixtures. 
The Zimont and KaLe expressions perform well, except for the leanest mixture, where there is a slight underestimation of the main combustion duration. It must be noted that this operation point was significantly affected by cycle-to-cycle variations ( $>30 \%$, see Table A.5) which compromises the

440 reliability of the experimental results. The underprediction is even worse for the Damköhler model due to the its low $u_{l}$ sensitivity.

Finally, the influence of external EGR on ignition delay and 10-90\% burn time is illustrated in Figure 12. Because of the challenges associated with the control and measurement of EGR\%, this factor was not included in the Response Surface Method dataset (Table A.5). Instead, some measurements were done at $1500 \mathrm{rpm}$, wide open throttle, optimal spark timing and with varying amounts of EGR\% (see Table A.6).

Next to the different turbulent combustion models, the predictive performance of the default methanol $u_{l}$ correlation in GT-Power (in combination 450 with the Zimont $u_{t e}$ model) is tested. The residual gas term in this correlation is that of Rhodes and Keck [14] developed for gasoline.

For the ignition delay, all models employing the new $u_{l}$ correlation produce acceptable results. The Damköhler model underpredicts the effect of EGR because of its relative insensitivity to $u_{l}$. The Rhodes and Keck resid455 ual gas term produces a too steep decline in $u_{l}$ with higher EGR levels (see Figure 1), leading to an overestimation of the ignition delay.

With regard to the main combustion duration, the respective over- and underpredictions by the Rhodes and Keck residual gas term and the Damköhler $u_{t e}$ model are even more marked. The turbulent burning velocity expression 460 of Zimont produces the best results among the considered models. It must be noted that the simulation results are very sensitive to the EGR\% (see section 4.1). Both estimated internal EGR\% and measured external EGR\% are subject to absolute errors in the order of $1-3 \%$. This makes it difficult to draw firm conclusions regarding the relative performance of the different turbulent

465 combustion models. Further validation regarding the effect of residuals on combustion and possible cross-effects of temperature and $\phi$ remain desirable.

\section{Knock model}

The predictive performance of the knock model using the new $\tau$ correlation for methanol was compared against existing correlations in an earlier publication of the current authors [34]. A crucial performance indicator of the knock prediction models is their ability to distinguish between knocking 
and non-knocking conditions and predict the knock limited spark advance (KLSA). Measured and predicted values for KLSA are plotted as function of CR, TP and $\phi$ in Figure 13.

475 A first observation is that the correlation of Douaud \& Eyzat [18] does not yield realistic values for the KLSA. This is due to the low temperature sensitivity of this correlation [34], which was constructed for primary reference fuels. For compression ratios below 10 the KLSA is underpredicted by all models. This is probably due to an overestimated heat transfer coefficient at higher compression ratios by the Woschni model, which emphasizes that a correct estimation of the in-cylinder unburned mixture temperatures is of crucial importance for knock prediction.

The effect of reduced load (throttle position closer to $90^{\circ}$ ) on the KLSA is best reproduced by the current correlation and that of Yates et al. Both correlations were developed for methanol based on chemical kinetics calculations and consequently behave similarly. Small differences are the result of subtle effects of EGR on autoignition kinetics, which are included in the new correlation. Note that the local minimum for KLSA vs. TP is actually an artifact of the fact the measurements were executed according to a Design of Experiments matrix and a 2nd degree polynomial was fitted to the results. The measurements at stoichiometric operation and $\mathrm{TP}=63^{\circ}$ and $\mathrm{TP}=75^{\circ}$ result in very similar KLSA of $14-15^{\circ}$ ca BTDC.

The largest model inaccuracies appear when changing equivalence ratio. Clearly there is some phenomenon at play that is not well captured by the employed models. Possibly, the effect of equivalence ratio on the autoignition delay is not correctly reproduced by the chemical kinetics mechanism. However, this does not explain the extent of the discrepancy.

Probably, the observed behavior is a result of the combined effects of evaporation cooling, mixture richness effects on the heat transfer to the cylinder walls and faster combustion resulting in less unburned mass when the autoignition conditions are reached. If the mass of autoigniting end-gas is very low, the resulting pressure oscillations might be too low to be detected. Another contributing factor might be the deteriorating cyclic stability when leaning the mixture.

505 The expected effect of alcohol evaporation is discussed in the following section. 


\section{Breathing cycle model}

Although the primary focus of this work was on power cycle modeling, the gas dynamics during the breathing cycle were also included. The onedimensional fluid dynamics routines of GT-Power were used to build models of the intake and exhaust geometries of both test engines. The theoretical concepts and calibration methodology behind these routines are well described in [19]. As mentioned in Section 3.2, these models were used to calculate the residual gas fraction at intake valve closing time. Here, we return to the previous comments on the impact of fuel evaporation on the predictions of burning rate and knock occurrence. GT-Power can be used to estimate the impact of the assumption concerning fuel evaporation; this is reported at the end of this section. Another aspect that requires some special attention is the effect of alcohol injection on the volumetric efficiency.

When fuel is injected in a PFI engine, two effects are at play.

- Upon injection of fuel, part of it vaporizes and replaces air in the vicinity of the injector, reducing volumetric efficiency (VE).

- The charge cooling effect of fuel vaporization will make for a more dense mixture, increasing VE.

The balance between these effects is determined by the stoichiometric air-to-fuel ratio, the vapor density and especially the heat of vaporization. In PFI engines running on gasoline, these effects have been shown to be balanced [19]. In alcohol fueled engines, on the other hand, the high latent heat of vaporization causes the cooling effect to be dominant, so this needs to be represented in the simulation model [34].

In GT-Power, the standard way to deal with fuel vaporization is to impose the fraction of fuel that is vaporized upon injection [19]. This fraction (30\% by default) will contribute to mixture cooling. The compliment of this fraction is assumed to remain in liquid suspension until just before ignition.

Figure 14 shows the measured and predicted VE from the full geometry gas dynamics model of the Audi engine [21]. Note that the volumetric efficiency is defined here solely based on air mass flow, as usually done with gasoline engines. The methanol mass flow is considerable (taking up much volume), consequently the VE for methanol in Fig. 14 is lower than for gasoline. If the volumetric efficiency was defined based on total mass flow (air+fuel) it would be higher for methanol. 
To illustrate the vaporization cooling effect, $30 \%$ of the fuel is assumed to vaporize upon injection for both gasoline and methanol. The volumetric effiency for methanol operation is seen to be significantly overestimated due to an overestimated vaporization cooling effect. This was also reported by Lauer et al. for simulations of PFI ethanol engines [47].

The predicted mixture cooling by methanol evaporation can be reduced by setting the vaporized fuel fraction to a lower value. However, the resulting higher liquid fuel fraction in suspension leads to wrong pressure prediction during compression. The reason for this is the way GT-Power calculates the ratio of specific heats $\gamma=c_{p} / c_{v}$, which is related to the compression slope. In GT-Power $\gamma$ is calculated as the weighted average of the gaseous and liquid mixture components' $\gamma$. As opposed to gasoline, the $c_{p}$ (and thus $\gamma$ ) of gaseous and liquid methanol differ a lot (see Figure 15). Imposing that none of the fuel will evaporate until ignition, will thus lead to an underestimation of the compression slope for methanol.

So for methanol and ethanol, a low setting of the vaporized fuel fraction leads to an underpredicted compression slope, while a high setting causes the VE to be overestimated. In reality, however, other phenomena are at play. Charge cooling is limited because part of the vaporization heat is absorbed from the engine structure (intake port and valves). This is especially the case when a puddle is formed on the intake port wall [47].

Generally, the injected fuel can be categorized in three components: immediately vaporized fuel, liquid fuel in suspension and a liquid fraction on the intake port wall. For PFI gasoline engines, $10-20 \%$ of the fuel vaporizes instantly, 50-60\% vaporizes from the liquid fuel film and the rest stays in liquid suspension [48]. Since light alcohols have a lower vapor pressure, are less volatile and need to be injected at higher volumes than gasoline, the fraction of fuel in the liquid film can be expected to be higher.

GT-Power offers the ability to model fuel deposition, evaporation, droplet entrainment and transport of liquid fuel to the cylinder by shear forces, thanks to the model described in [49]. This model is generally only required to study transient phenomena, but proved crucial to accurately predict the VE in alcohol-fueled engines. The model was successfully used to predict both VE and compression slope in the gas dynamics models used for this work [21]. Figure 14 shows that the VE for methanol operation on the Audi engine is correctly predicted when the puddling model is used. Modeling of wall wetting will also be required when considering engines with direct injection. 
580

As reported in Section 5, one of the possible reasons for the inaccuracies of the knock predictions is the assumption that all injected methanol entered the cylinder fully vaporized. Given the discussion above, a test case was simulated with the amount of evaporated methanol set to $90 \%$ instead of $100 \%$. The resulting mixture cooling effect led to significantly better correspondence for the predicted KLSA throughout the $\phi$ range. Future work should focus on the thermal effects of varying $\phi$ (both evaporative cooling and wall heat transfer) by applying the same heat flux measurement techniques as used in $[42]$.

\section{Conclusion}

In this work, submodels developed specifically for light alcohol fuels, were implemented in a quasi-dimensional engine simulation code and validated against a series of measurements obtained on two single cylinder engines and at various compression ratios, loads, ignition timings, rpm, equivalence ratio and $\mathrm{EGR} \%$.

A sensitivity analysis of the power cycle simulation's results stressed the importance of the laminar burning velocity correlation and boundary conditions obtained from gas dynamics' simulation (amount and composition of the in-cylinder mixture) for the model's accuracy. The simulation results also appeared to be very sensitive to in-cylinder turbulence, bulk flow and flame center movements, for which no direct data was available.

The combustion routines were validated against a database of cylinder pressure traces obtained on the two engines. The new laminar burning velocity correlations were shown to predict the effects of varying mixture composition much better than existing correlations. A comparison confirmed that turbulent burning velocity models including thermodiffusive properties performed better than simpler models.

A preliminary validation of the new knock prediction model for methanol illustrated that despite the gross simplifications, the developed model can yield useful results for quantities relevant to knock. The largest model inaccuracies occurred for varying equivalence ratio. This is probably caused by an incorrect representation of the thermal effects of changing equivalence ratio. The use of more advanced wall heat transfer models and inclusion of evaporation cooling might improve this.

To get a feel for the impact of evaporation cooling, a breathing cycle model was used that included the dynamics of fuel puddling. This confirmed 
the importance of including this, and proved necessary to accurately predict the volumetric efficiency of PFI engines running on methanol or ethanol.

\section{Acknowledgements}

J. Vancoillie gratefully acknowledges a Ph. D. fellowship (FWO09/ASP /030) and a travel grant for a long stay abroad (V407312N) of the Research Foundation - Flanders (FWO). L. Sileghem also acknowledges a Ph. D. fellowship (FWO11/ASP/056) of the Research Foundation - Flanders (FWO).

\section{Nomenclature}

$\begin{array}{ll}\text { Abbreviation } & \\ A T D C & \text { after top dead center } \\ C F M & \text { coherent flame model } \\ C F R & \text { cooperative fuel research } \\ C R & \text { compression ratio } \\ E V O & \text { exhaust valve opening } \\ G U E S T & \text { Ghent University Engine Simulation Tool } \\ h t r & \text { heat transfer } \\ I M E P & \text { indicated mean effective pressure } \\ I T & \text { ignition timing } \\ I V C & \text { intake valve closing } \\ K L S A & \text { knock limited spark advance } \\ K O & \text { knock onset } \\ O H C & \text { overhead camshaft } \\ O H V & \text { overhead valve } \\ P F I & \text { port fuel injection } \\ Q D & \text { quasi dimensional } \\ R M S & \text { root mean square } \\ S I & \text { spark ignition } \\ T D C & \text { top dead center } \\ T P & \text { throttle position } \\ V E & \text { volumetric efficiency } \\ & \end{array}$




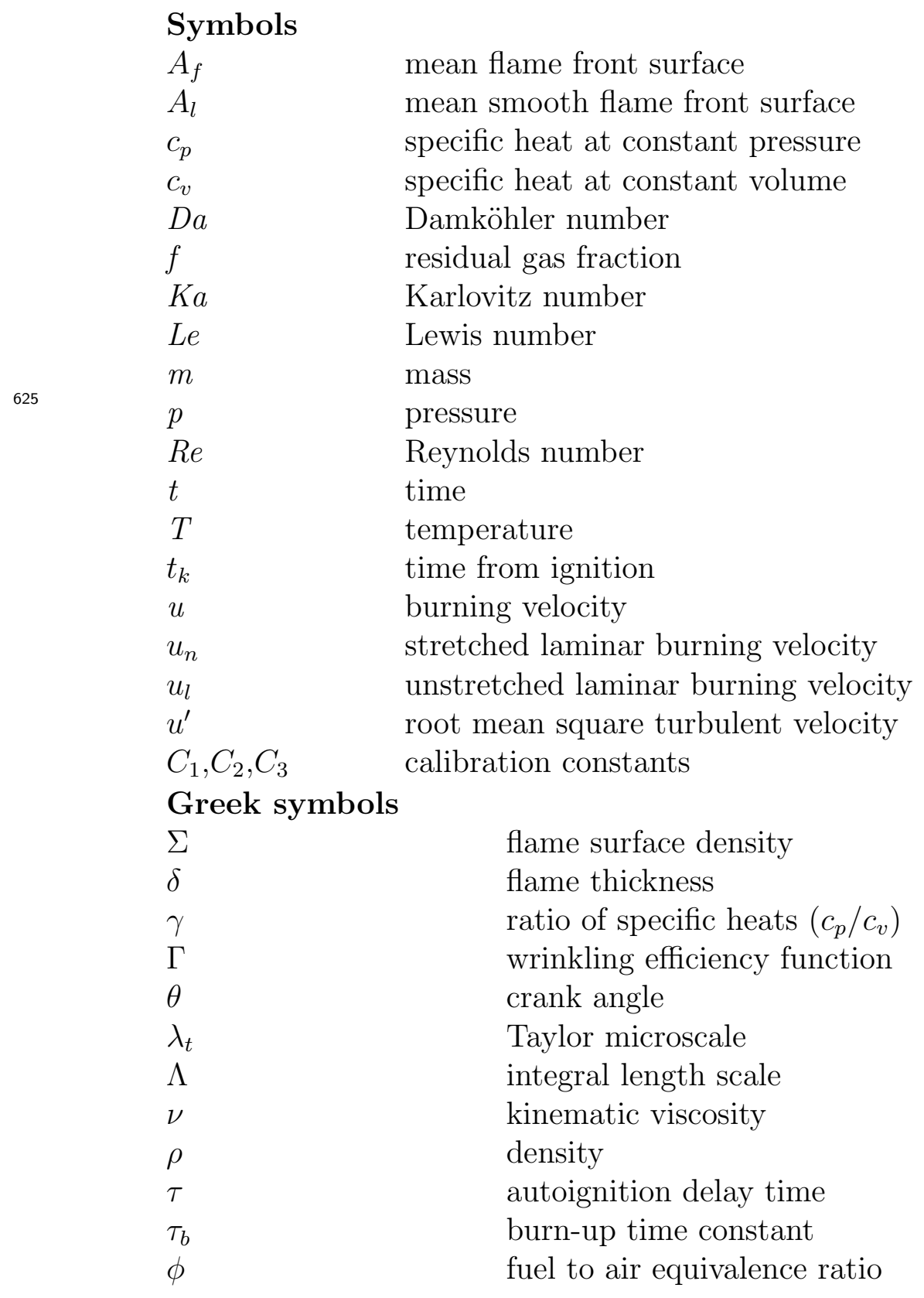




$\begin{array}{ll}\text { Subscripts } & \\ 0 & \text { reference condition } \\ b & \text { burned } \\ e & \text { entrained gas } \\ l & \text { laminar } \\ t & \text { turbulent } \\ u & \text { unburned }\end{array}$

\section{References}

[1] Vancoillie J, Demuynck J, Sileghem L, Van De Ginste M, Verhelst S, Brabant L, et al. The potential of methanol as a fuel for flex-fuel and dedicated spark-ignition engines. Applied Energy 2013;102:140-9.

[2] Clairotte M, Adam T, Zardini A, Manfredi U, Martini G, Krasenbrink A, et al. Effects of low temperature on the cold start gaseous emissions from light duty vehicles fuelled by ethanol-blended gasoline. Applied Energy 2013;102:44-54.

[3] Maurya R, Agarwal A. Experimental study of combustion and emission characteristics of ethanol fuelled port injected homogeneous charge compression ignition (HCCI) combustion engine. Applied Energy 2011;88:1169-80.

[4] Maurya R, Agarwal A. Statistical analysis of the cyclic variations of heat release parameters in HCCI combustion of methanol and gasoline. Applied Energy 2012;89:228-36.

[5] Vancoillie J, Christensen M, Nilsson EJK, Verhelst S, Konnov AA. Temperature dependence of the laminar burning velocity of methanol flames. Energy \& Fuels 2012;26(3):1557-64.

[6] Pearson R, Turner J, Eisaman M, Littau K. Extending the supply of alcohol fuels for energy security and carbon reduction. SAE International; 2009. SAE paper no. 2009-01-2764.

[7] Verhelst S, Sheppard CGW. Multi-zone thermodynamic modelling of spark-ignition engine combustion - an overview. Energy Conversion and Management 2009;50(5):1326-35. 
[8] Verhelst S, Sierens R. A quasi-dimensional model for the power cycle of a hydrogen-fuelled ICE. International Journal of Hydrogen Energy 2007;32(15):3545-54.

[9] Mohanan P, Babu MKG. A simulation model for a methanol fueled turbocharged multi-cylinder automotive spark ignition engine. SAE International; 1991. SAE paper no. 912417.

[10] Westbrook CK, Dryer FL. Prediction of laminar flame properties of methanol-air mixtures. Combustion and Flame 1980;37:171-92.

[11] Brown AG, Stone CR, Beckwith P. Cycle-by-cycle variations in spark ignition engine combustion - part i: flame speed and combustion measurements and a simplified turbulent combustion model. SAE International; 1996. SAE paper no. 960612.

[12] Gibbs GJ, Calcote HF. Effect of molecular structure on burning velocity. Journal of Chemical \& Engineering Data 1959;4(3):226-37.

[13] Metghalchi M, Keck JC. Burning velocities of mixtures of air with methanol, isooctane, and indolene at high pressure and temperature. Combustion and Flame 1982;48:191-210.

[14] Rhodes DB, Keck JC. Laminar burning speed measurements of indoleneair-diluent mixtures at high pressures and temperatures. SAE International; 1985. SAE paper no. 850047.

[15] Pourkhesalian AM, Shamekhi AH, Salimi F. Alternative fuel and gasoline in an SI engine: A comparative study of performance and emissions characteristics. Fuel 2010;89(5):1056-63.

[16] Bougrine S, Richard S. Modelling and simulation of the combustion of ethanol blended fuels in a si engine using a 0d coherent flame model. SAE International; 2009. SAE paper no. 2009-24-0016 .

[17] Gülder OL. Burning velocities of ethanol isooctane blends. Combustion and Flame 1984;56(3):261-8.

[18] Douaud AM, Eyzat P. Four-octane-number method for predicting the anti-knock behavior of fuels and engines. SAE International; 1978. SAE paper no. 780080 . 
[19] Gamma Technologies . GT-Suite Version 7.3 User's Manual. Westmont, IL, USA: Gamma Technologies; 2012.

[20] Vancoillie J, Demuynck J, Galle J, Verhelst S, van Oijen JA. A laminar burning velocity and flame thickness correlation for ethanol-air mixtures valid at spark-ignition engine conditions. Fuel 2012;102:460-9.

[21] Vancoillie J. Modeling the combustion of light alcohols in sparkignition engines. Ph.D. thesis; Ghent University; 2013. Doi: http://hdl.handle.net/1854/LU-4144604.

[22] Vancoillie J, Sharpe G, Lawes M, Verhelst S. The turbulent burning velocity of methanol-air mixtures. submitted to Fuel (2013) 2013;

[23] Blizard NC, Keck JC. Experimental and theoretical investigation of turbulent burning model for internal combustion engines. SAE International; 1974. SAE paper no. 740191.

[24] Gülder OL. Turbulent premixed flame propagation models for different combustion regimes. Symposium (International) on Combustion $1991 ; 23(1): 743-50$.

[25] Abdel-Gayed RG, Bradley D, Lawes M. Turbulent burning velocities: A general correlation in terms of straining rates. Proceedings of the Royal Society of London A Mathematical and Physical Sciences 1987;414(1847):389-413.

[26] Zimont VL. Gas premixed combustion at high turbulence. turbulent flame closure combustion model. Experimental Thermal and Fluid Science 2000;21(1-3):179-86.

[27] Lipatnikov AN, Chomiak J. Turbulent flame speed and thickness: phenomenology, evaluation, and application in multi-dimensional simulations. Progress in Energy and Combustion Science 2002;28(1):1-74.

[28] Muppala SPR, Aluri NK, Dinkelacker F, Leipertz A. Development of an algebraic reaction rate closure for the numerical calculation of turbulent premixed methane, ethylene, and propane/air flames for pressures up to $1.0 \mathrm{mpa}$. Combustion and Flame 2005;140(4):257-66. 
[29] Richard S, Bougrine S, Font G, Lafossas FA, Berr FL. On the reduction of a 3D CFD combustion model to build a physical 0D model for simulating heat release, knock and pollutants in SI engines. Oil and Gas Science and Technology - Rev IFP 2009;64(3):223-42.

[30] Bradley D, Lawes M, Liu K, Verhelst S, Woolley R. Laminar burning velocities of lean hydrogen-air mixtures at pressures up to 1.0 MPa. Combustion and Flame 2007;149(1-2):162-72.

[31] Vancoillie J, Verhelst S, Demuynck J. Laminar burning velocity correlations for methanol-air and ethanol-air mixtures valid at SI engine conditions. SAE International; 2011. SAE paper no. 2011-01-0846.

[32] Vancoillie J, Christensen M, Nilsson EJK, Verhelst S, Konnov AA. The effects of dilution with nitrogen and steam on the laminar burning velocity of methanol at room and elevated temperatures. Fuel 2013;105:732-8.

[33] Vancoillie J, Sharpe G, Lawes M, Verhelst S. Laminar burning velocities and markstein lengths of methanol-air mixtures at pressures up to 1.0 mpa. Fuel 2013;

[34] Vancoillie J, Sileghem L, Verhelst S. Development and validation of a knock prediction model for methanol-fuelled si engines. SAE International; 2013. SAE paper no. 2013-01-1312.

[35] Yates A, Bell A, Swarts A. Insights relating to the autoignition characteristics of alcohol fuels. Fuel 2010;89(1):83-93.

[36] Livengood JC, Wu PC. Correlation of autoignition phenomena in internal combustion engines and rapid compression machines. Symposium (International) on Combustion 1955;5(1):347-56.

[37] Li J, Zhao ZW, Kazakov A, Chaos M, Dryer FL, Scire JJ. A comprehensive kinetic mechanism for $\mathrm{CO}, \mathrm{CH} 2 \mathrm{O}$, and $\mathrm{CH} 3 \mathrm{OH}$ combustion. International Journal of Chemical Kinetics 2007;39(3):109-36.

740

[38] Demuynck J, De Paepe M, Huisseune H, Sierens R, Vancoillie J, Verhelst $\mathrm{S}$. Investigation of the influence of engine settings on the heat flux in a hydrogen- and methane-fueled spark ignition engine. Applied Thermal Engineering 2011;31(6-7):1220-8. 
[39] Vancoillie J, Verhelst S, Demuynck J, Galle J, Sileghem L, Ginste MVD. Experimental evaluation of lean-burn and EGR as load control strategies for methanol engines. SAE International; 2012. SAE paper no. 201201-1283.

[40] Worret R, Bernhardt S, Schwarz F, Spicher U. Application of different cylinder pressure based knock detection methods in spark ignition engines. SAE International; 2002. SAE paper no. 2002-01-1668.

[41] Box GEP, Draper NR. Response Surfaces, Mixtures, and Ridge Analyses. Hoboken, New Jersey: John Wiley \& Sons; 2007.

[42] Demuynck J. A fuel independent heat transfer correlation for premixed spark ignition engines. Ph.D. thesis; Ghent University; 2012. Doi: http://hdl.handle.net/1854/LU-3079977.

[43] Hattrell T. A computational and experimental study of spark ignition engine combustion. Ph.D. thesis; University of Leeds; 2007.

[44] Woschni G. A universally applicable equation for the instantaneous heat transfer coefficient in the internal combustion engine. SAE International; 1967. SAE paper no. 670931.

[45] Bayraktar H. Experimental and theoretical investigation of using gasoline-ethanol blends in spark-ignition engines. Renewable Energy 2005;30(11):1733-47.

[46] Verhelst S. A study of the combustion in hydrogen-fuelled internal combustion engines. Ph.D. thesis; Ghent University; 2005. Doi: dx.doi.org/1854/3378.

[47] Lauer T, Heiss M, Fischer S, Klein M. Prediction of the wall film formation and performance of an engine operated with the ethanol blend E85. In: 13th EAEC European Automotive Congress. Valencia; 2011,.

[48] Chen G, Suresh K. Unsteady multiphase intake flow in a port-injected gasoline engine. SAE International; 1996. SAE paper no. 960074.

[49] Morel T, Wahiduzzaman S. Effect of manifold wall wetting and fuel evaporation on transient engine operation. In: 8th Symposium on The Working Process of the Internal Combustion Engine. Graz, Germany; $775 \quad 2001$, . 
[50] Rowley R, Wilding W, Oscarson J, Yang Y, Zundel N, Daubert T, et al. DIPPR data compilation of pure compound properties. New York: Design Institute for Physical Properties, AIChE; 2003.

[51] Morel T, Rackmil CI, Keribar R, Jennings M. Model for heat transfer and combustion in spark ignited engines and its comparison with experiments. SAE International; 1988. SAE paper no. 880198.

[52] Hall MJ, Bracco FV. A study of velocities and turbulence intensities measured in firing and motored engines. SAE International; 1987. SAE paper no. 870453 .

[53] Morel T, Keribar R. A model for predicting spatially and time resolved convective heat transfer in bowl-in-piston combustion chambers. SAE International; 1985. SAE paper no. 850204.

[54] Bozza F, Gimelli A, Merola SS, Vaglieco B. Validation of a fractal combustion model through flame imaging. SAE International; 2005. SAE paper no. 2005-01-1120.

[55] Driscoll JF. Turbulent premixed combustion: Flamelet structure and its effect on turbulent burning velocities. Progress in Energy and Combustion Science 2008;34(1):91-134.

\section{List of Tables}

1 Engine specifications. Atm. = atmospheric. . . . . . . . . . 28

2 Parameter values for power cycle sensitivity analysis . . . . . 28

A.3 Measurement conditions: neat methanol operation on CFR engine. IT in ${ }^{\circ} \mathrm{ca}$ ATDC, $\lambda_{m}$ denotes the value for $\lambda$ calculated from the measured air and fuel mass flow rates; $\lambda_{s}$ denotes the value measured with the wide band $\lambda$ sensor. $600 \mathrm{rpm}$. TP: $0^{\circ}=$ open, $90^{\circ}=$ closed. . . . . . . . . . . . . . . . . . . . 42

A.4 Measurement conditions: neat ethanol operation on CFR engine. IT in ${ }^{\circ}$ ca ATDC, $\lambda$ from $\lambda$ sensor. $600 \mathrm{rpm}$. TP: $0^{\circ}=$ open, $90^{\circ}=$ closed. . . . . . . . . . . . . . . 43

A.5 Measurement conditions: neat methanol operation on Audi engine . IT in ${ }^{\circ} \mathrm{ca}$ ATDC. TP: $90^{\circ}=$ open, $0^{\circ}=$ closed. . . . . 44 
A.6 Measurement conditions: neat methanol operation on Audi engine with external EGR . IT in ${ }^{\circ} \mathrm{ca}$ ATDC. TP: $90^{\circ}=$ open, $0^{\circ}=$ closed. . . . . . . . . . . . . . . . . . . 45

A.7 Calibration constants for methanol operation on the CFR engine . . . . . . . . . . . . . . . . 45

A.8 Calibration constants for ethanol operation on the CFR engine 45

A.9 Calibration constants for methanol operation on the Audi engine . . . . . . . . . . . . . . . 46

\section{List of Figures}

1 Comparison of predicted $u_{l}$ as a function of $\phi$ (left) and residual gas correction terms (right). 'Vancoillie' refers to the correlation developed [31]. . . . . . . . . . . . . . . . . . . . . . 29

2 Relative change in $0-2 \%$ and $10-90 \%$ burn time caused by the uncertainties in Table 2 . . . . . . . . . . . . . . . . . . . . . 29

3 Relative change in peak cylinder pressure caused by the uncertainties in Table 2 . . . . . . . . . . . . . . . . 30

4 Relative change in peak cylinder temperature caused by the uncertainties in Table 2 . . . . . . . . . . . . . . . . 30

5 Comparison of $u_{t}$ models for varying compression ratio. Left - methanol. Right - ethanol. . . . . . . . . . . . . . . 31

6 Comparison of $u_{t}$ models for varying ignition timing. Left methanol. Right - ethanol. . . . . . . . . . . . . . . 31

7 Comparison of $u_{t}$ models for varying throttle position for methanol. 32

8 The estimated level of internal EGR in the CFR engine as a function of throttle position . . . . . . . . . . . . 32

9 Comparison of $u_{t}$ correlations for varying $\phi$ and fixed TP. Left - methanol. Right - ethanol. . . . . . . . . . . . . . 33

10 Comparison of $u_{t}$ correlations for varying engine speed. . . . . 33

83511 Comparison of $u_{t}$ correlations for varying mixture equivalence ratio ...................... . . 34

12 Comparison of $u_{l}$ and $u_{t}$ correlations for varying amounts of external EGR . . . . . . . . . . . . . . . . . . . . 34

13 Measured and simulated knock limited spark advance (KLSA) as a function of $\mathrm{CR}, \mathrm{TP}$ and $\lambda$. The largest model inaccuracies occur for varying equivalence ratio. 
14 Measured and predicted VE for the Audi engine. If $30 \%$ of the injected fuel is assumed to vaporize immediately the $\mathrm{VE}$ of methanol is overestimated. The use of a puddling model leads to correct predictions. . . . . . . . . . . . . . 36

15 The $c_{p}$ of methanol is more dependent on the state (liquid or vapor) than that of gasoline (represented by iso-octane) [50] . 37

Table 1: Engine specifications. Atm. = atmospheric.

\begin{tabular}{lll}
\hline Engine type & Audi & CFR \\
\hline Cylinders & 1 & 1 \\
Valves & 2 & 2 \\
Valvetrain & OHC & OHV \\
Bore & $77.5 \mathrm{~mm}$ & $83.06 \mathrm{~mm}$ \\
Stroke & $86.4 \mathrm{~mm}$ & $114.2 \mathrm{~mm}$ \\
Displacement & $407.3 \mathrm{cc}$ & $618.8 \mathrm{cc}$ \\
CR & $13.13: 1$ & variable \\
Injection & PFI & PFI \\
Induction & Atm. & Atm. \\
ECU $[$ MoTeC] & $\mathrm{M} 4$ & M4 \\
\hline
\end{tabular}

Table 2: Parameter values for power cycle sensitivity analysis

\begin{tabular}{lll}
\hline Parameter & Base value & $\Delta$ \\
\hline spark place & $15 \mathrm{~mm}$ excentric & $+5 \mathrm{~mm}$ \\
initial kernel radius & $0.5 \mathrm{~mm}$ & $+0.5 \mathrm{~mm}$ \\
dome height & $0.0 \mathrm{~mm}$ & $+5 \mathrm{~mm}$ \\
compression ratio & $10.17: 1$ & $+0.1: 1$ \\
$u^{\prime}$ & $1.7-1.9 \mathrm{~m} / \mathrm{s}$ & $+1 \mathrm{~m} / \mathrm{s}$ \\
heat transfer multiplier & 1 & +0.5 \\
volumetric efficiency & as measured & $+3 \%$ \\
$\Lambda$ & $0.10-0.12 \mathrm{~mm}$ & +0.05 \\
$u_{l}$ & {$[31]$} & $\mathrm{x}$ \\
EGR\% & $5-7 \%$ & $+3 \%$ \\
\hline
\end{tabular}



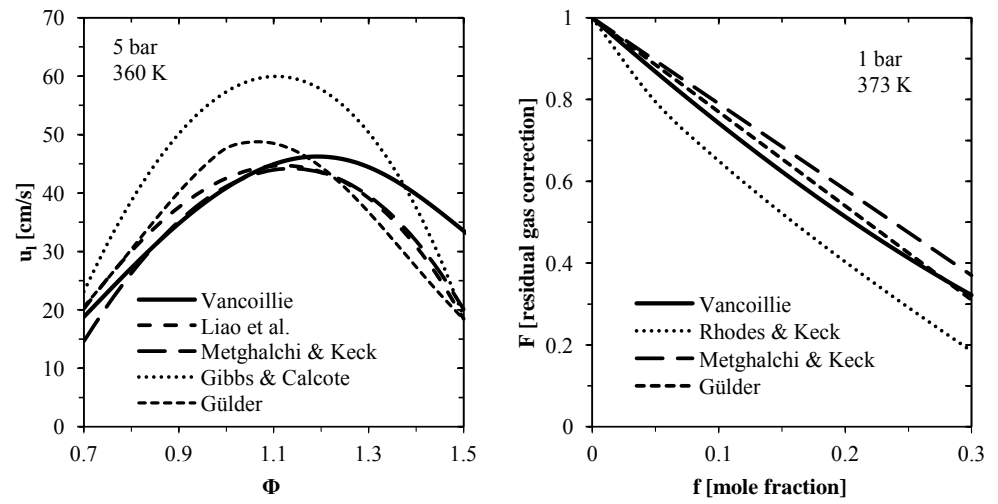

Figure 1: Comparison of predicted $u_{l}$ as a function of $\phi$ (left) and residual gas correction terms (right). 'Vancoillie' refers to the correlation developed [31].

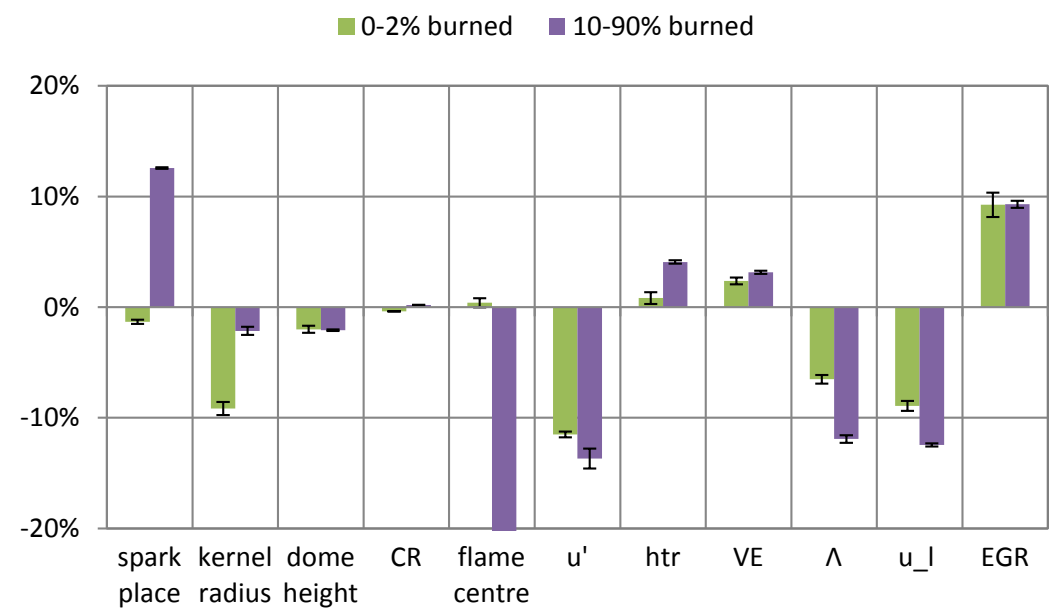

Figure 2: Relative change in $0-2 \%$ and $10-90 \%$ burn time caused by the uncertainties in Table 2 


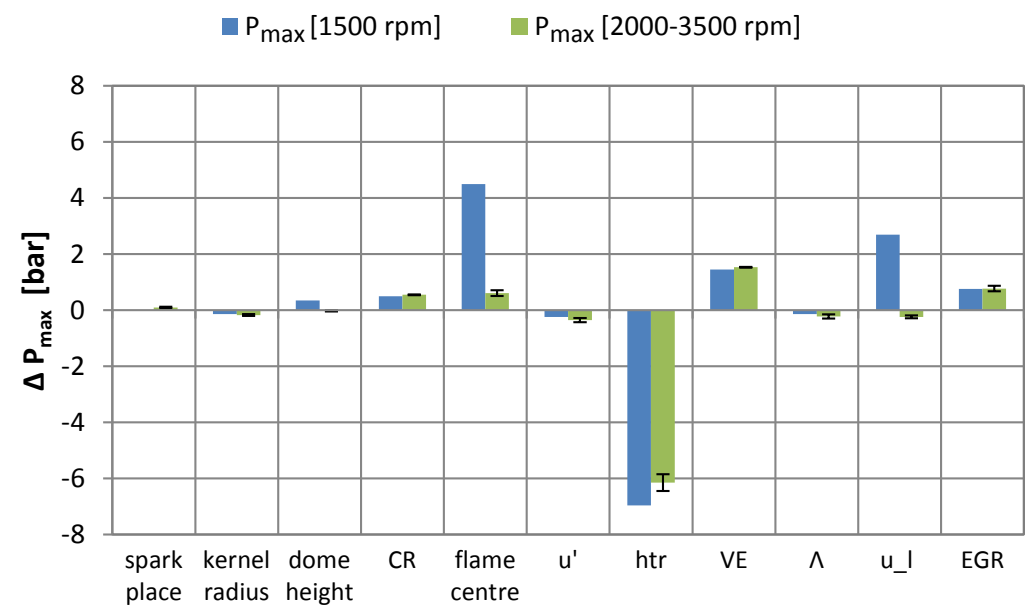

Figure 3: Relative change in peak cylinder pressure caused by the uncertainties in Table 2

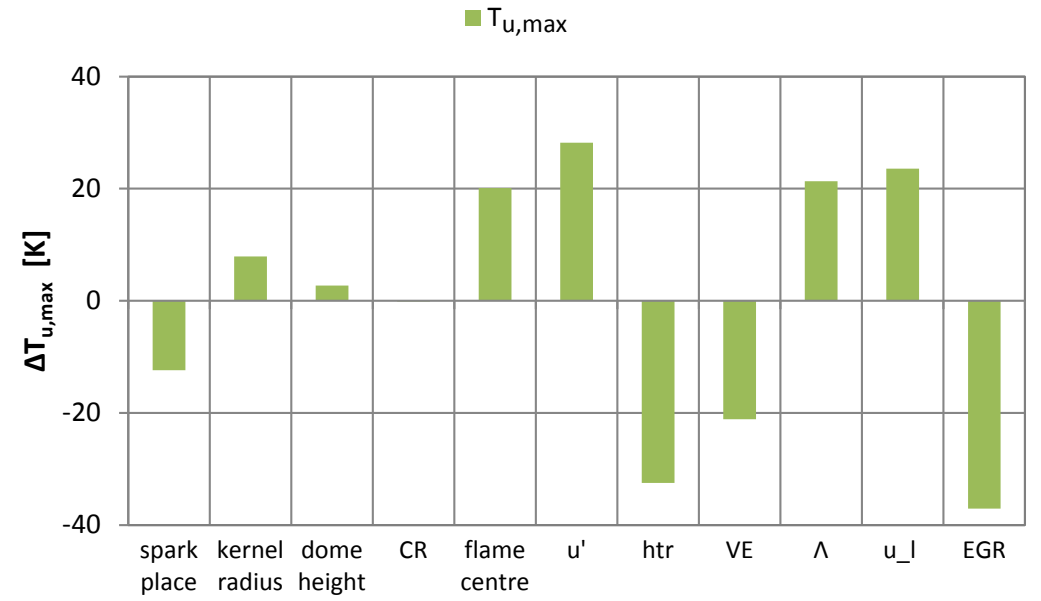

Figure 4: Relative change in peak cylinder temperature caused by the uncertainties in Table 2 

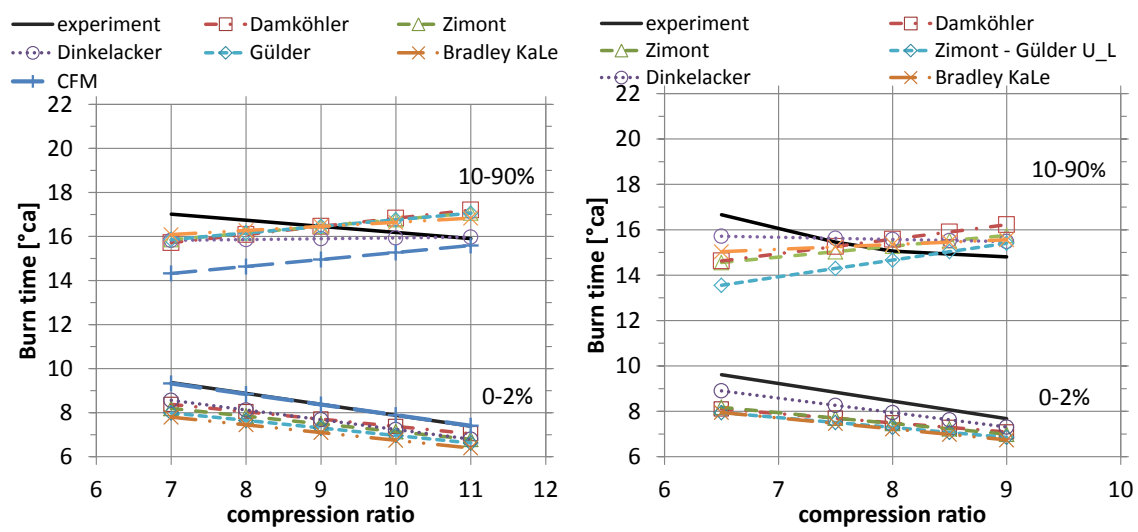

Figure 5: Comparison of $u_{t}$ models for varying compression ratio. Left methanol. Right - ethanol.
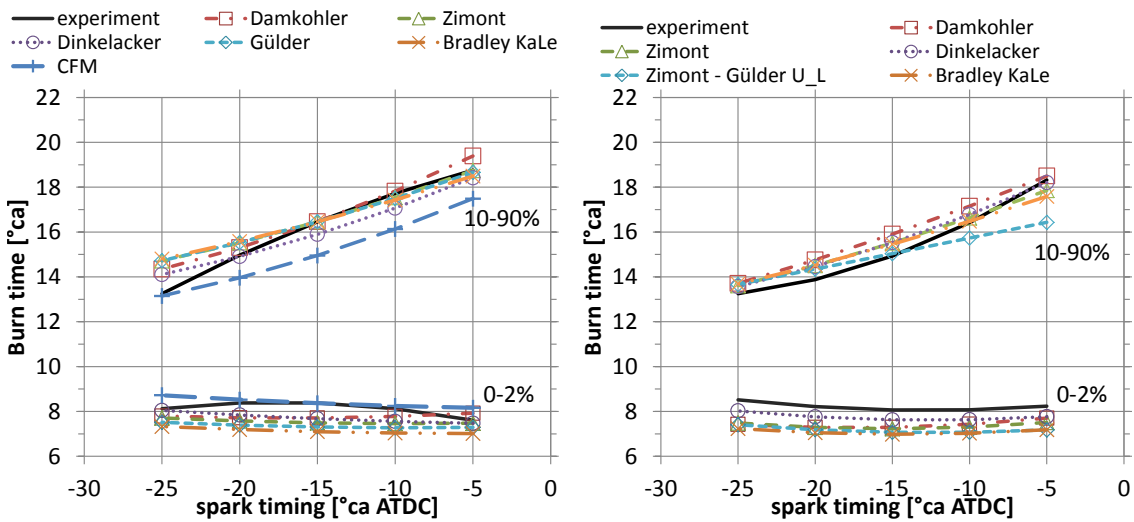

Figure 6: Comparison of $u_{t}$ models for varying ignition timing. Left - methanol. Right - ethanol. 


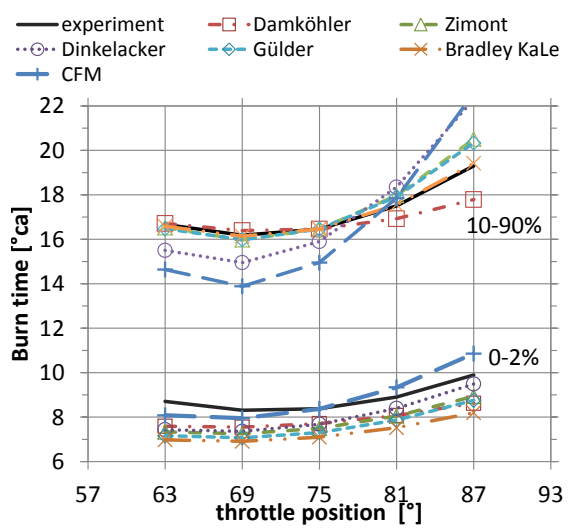

Figure 7: Comparison of $u_{t}$ models for varying throttle position for methanol.

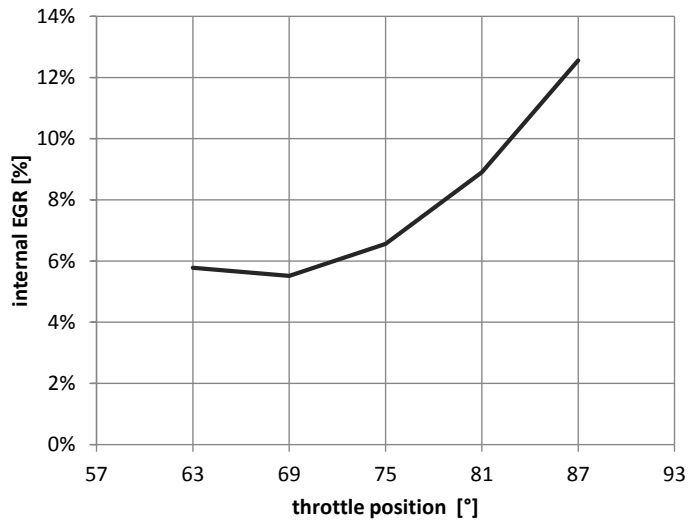

Figure 8: The estimated level of internal EGR in the CFR engine as a function of throttle position 

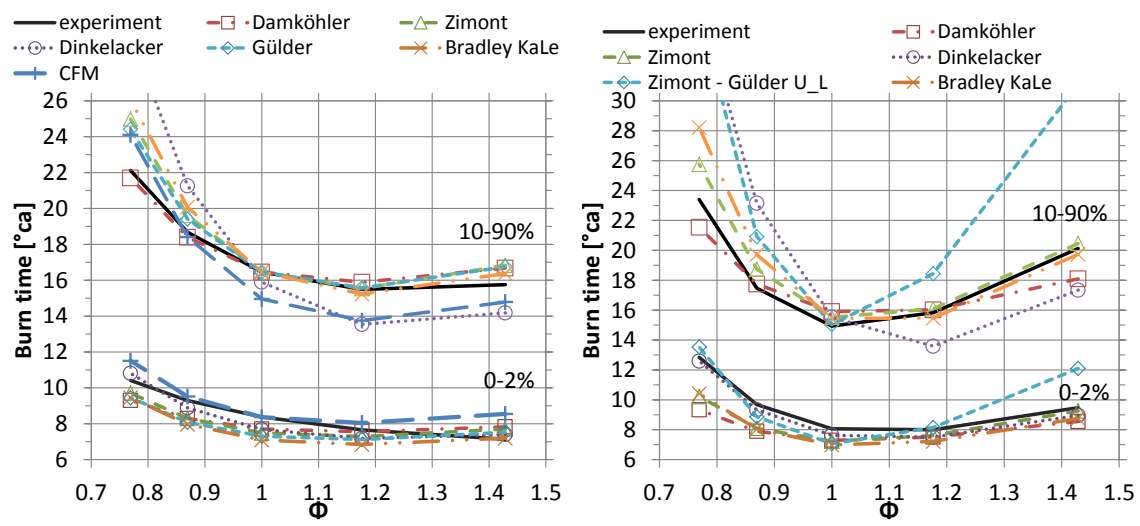

Figure 9: Comparison of $u_{t}$ correlations for varying $\phi$ and fixed TP. Left methanol. Right - ethanol.

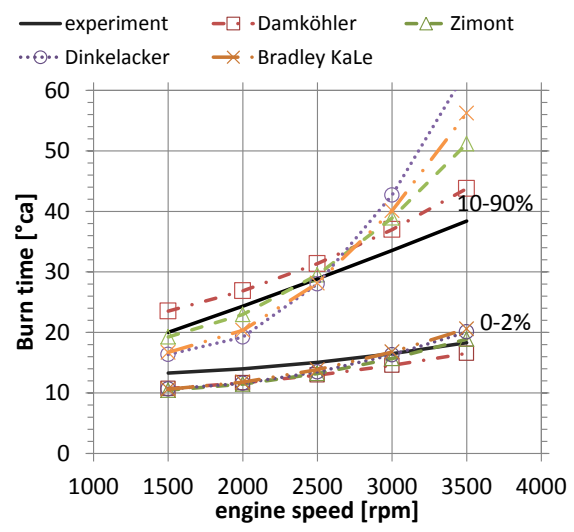

Figure 10: Comparison of $u_{t}$ correlations for varying engine speed. 


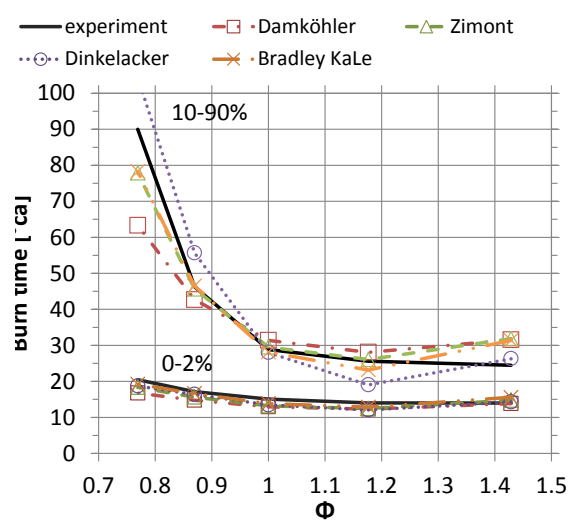

Figure 11: Comparison of $u_{t}$ correlations for varying mixture equivalence ratio

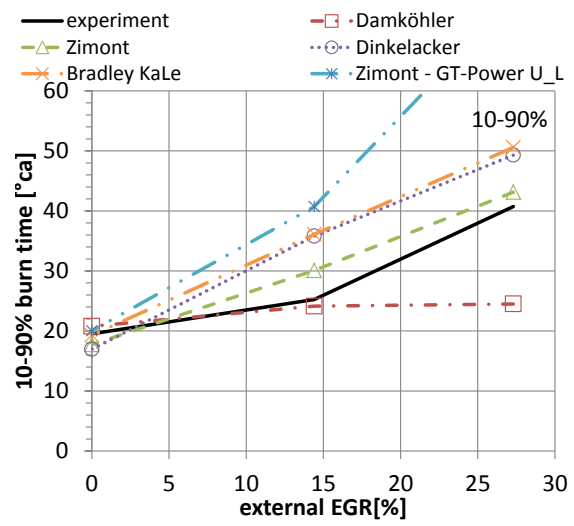

Figure 12: Comparison of $u_{l}$ and $u_{t}$ correlations for varying amounts of external EGR 

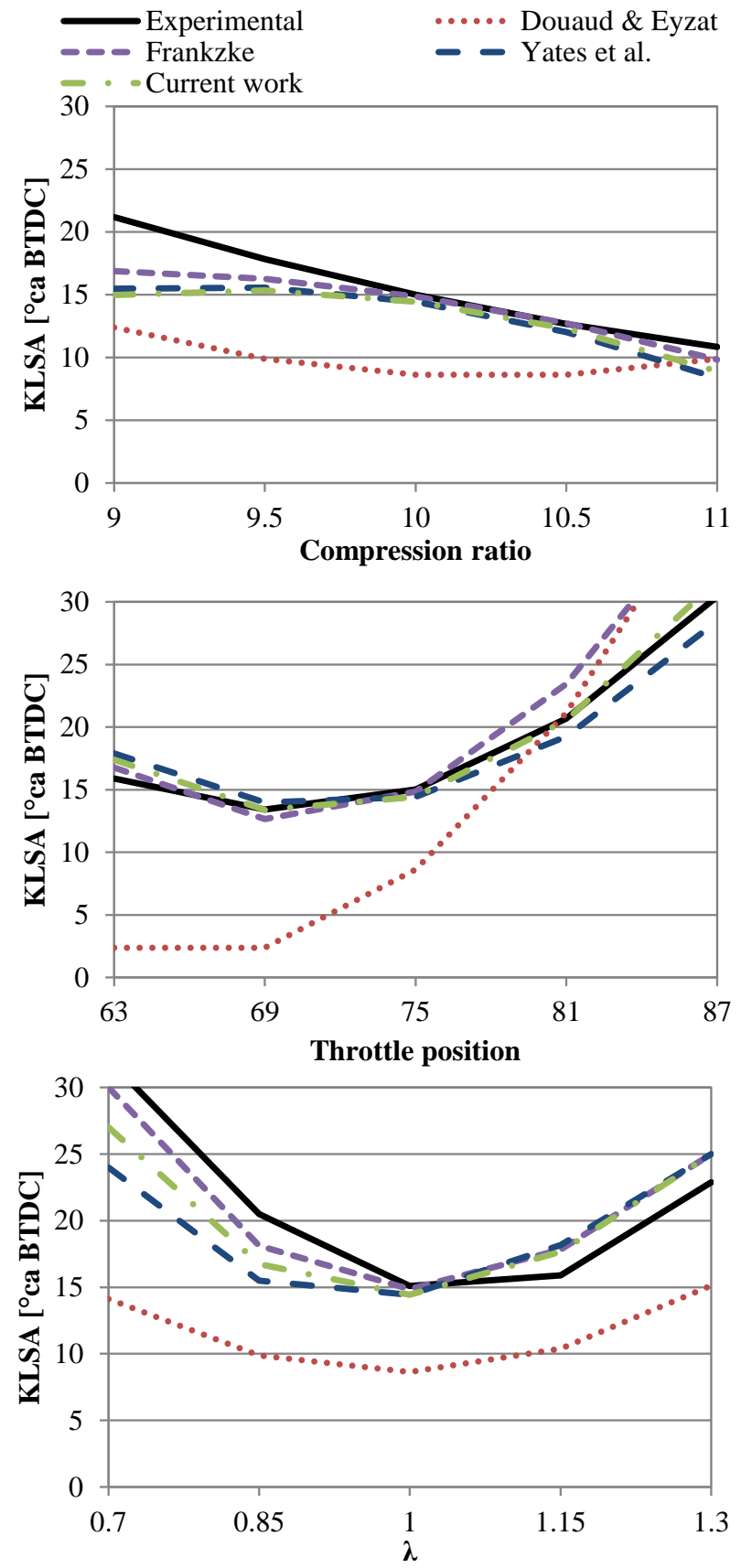

Figure 13: Measured and simulated knock limited spark advance (KLSA) as a function of CR, TP and $\lambda$. The largest model inaccuracies occur for varying equivalence ratio. 


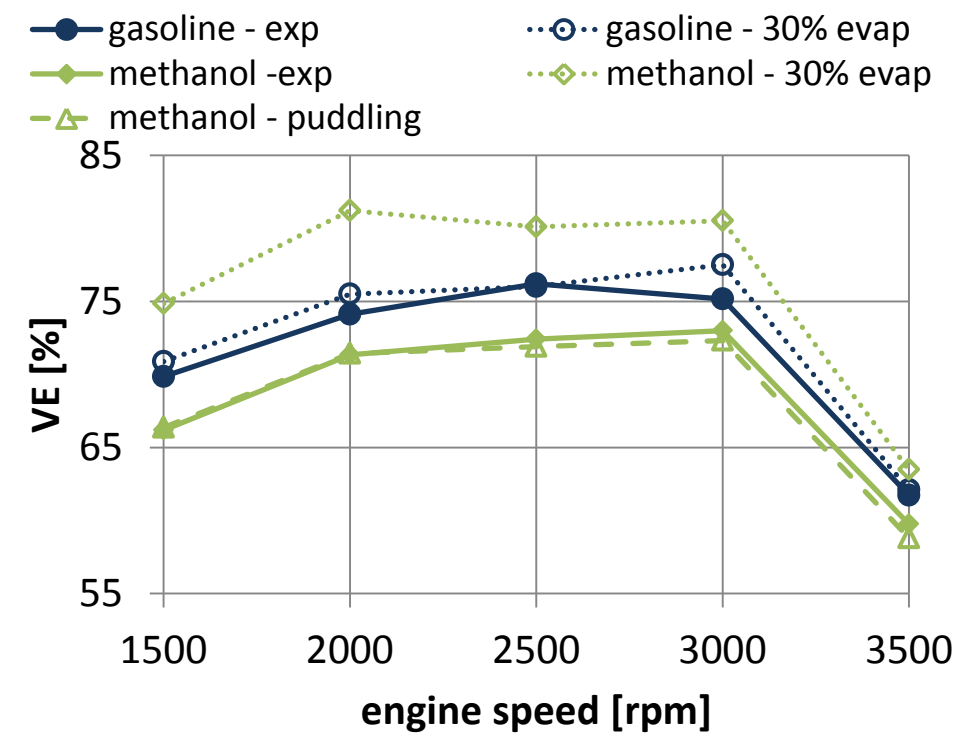

Figure 14: Measured and predicted VE for the Audi engine. If $30 \%$ of the injected fuel is assumed to vaporize immediately the VE of methanol is overestimated. The use of a puddling model leads to correct predictions. 


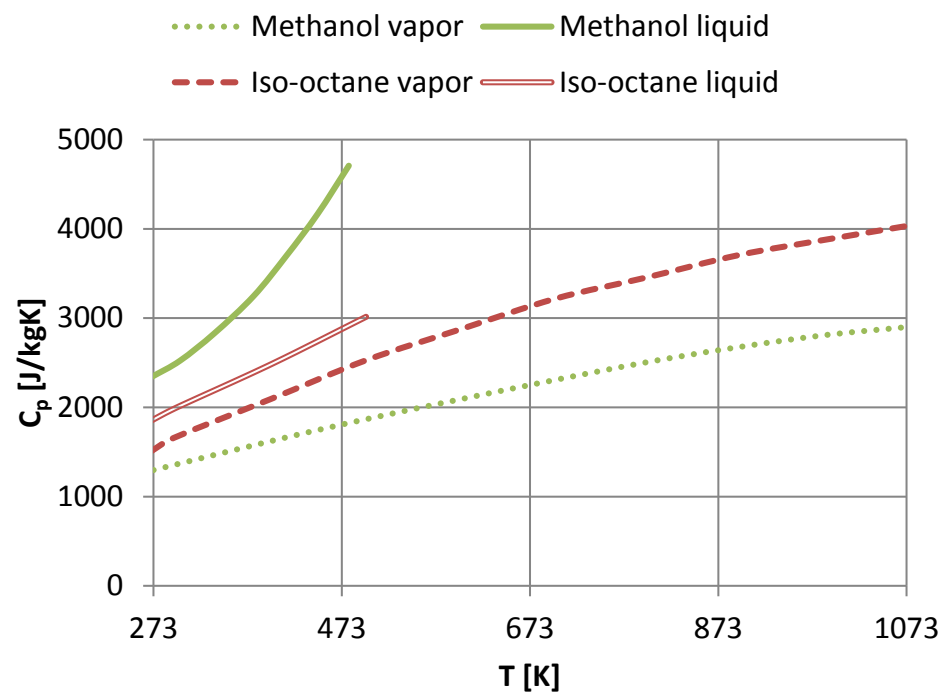

Figure 15: The $c_{p}$ of methanol is more dependent on the state (liquid or vapor) than that of gasoline (represented by iso-octane) [50]

\section{Appendix A.}

\section{Appendix A.1. Quasi-dimensional model assumptions}

The submodels and assumptions used in the current quasi-dimensional model are listed below. A more extensive discussion of the different submodels can be found in [21].

- Heat exchange is calculated separately for the cylinder liner, cylinder head and piston based on an extension of the Woschni model discussed in $[51]$

- The CFR (Cooperative Fuel Research) engine used for part of the validation of the simulation has a simple disc-shaped combustion chamber and ran at a fixed speed of $600 \mathrm{rpm}$. Therefore turbulence quantities are calculated using a very simple turbulence model based on measurements done in a similar engine [52]. The integral length scale $\Lambda$ is kept constant at $1 / 5$ of the minimum clearance height, and the rms turbulent velocity $u^{\prime}$ linearly decreases according to: 


$$
u^{\prime}=u_{T D C}^{\prime}\left(1-0.5 \frac{\theta-360}{45}\right)
$$

Where $u_{T D C}^{\prime}$ is the rms turbulent velocity at top dead centre (TDC), taken to be 0.75 times the mean piston speed, $\theta$ is the crank angle (360 at TDC of compression).

- For the Audi engine, the default turbulence model of GT-Power is used, which is a $k-\epsilon$ type model based on work of Morel et al. [53].

- The mass burning rate is derived from a turbulent combustion model. The one used in this work is based on the entrainment framework, where the rate of entrainment of unburned gas into the flame front is given by

$$
\frac{d m_{e}}{d t}=\rho_{u} A_{f} u_{t} e
$$

Where $m_{e}$ is the entrained mass, $A_{f}$ is the mean flame front surface, and $u_{t e}$ is the turbulent entrainment velocity. The mass entrainment into the flame front is then supposed to burn with a rate proportional to the amount of entrained unburned gas, with a time constant $\tau_{b}$ :

$$
\begin{aligned}
& \dot{m}_{b}=\frac{m_{e}-m_{b}}{\tau_{b}} \\
& \dot{m}_{b}=C_{3} \lambda_{T} / u_{l}
\end{aligned}
$$

Where $C_{3}$ is a calibration constant, $u_{l}$ is the laminar burning velocity and $\lambda_{t}$ is the Taylor length scale, given by:

$$
\begin{gathered}
\lambda_{t}=1.5 \Lambda / \sqrt{R e_{t}} \\
R e_{t}=u^{\prime} \Lambda / \nu_{u}
\end{gathered}
$$

Where $\Lambda$ is integral turbulent length scale and $\nu_{u}$ is the kinematic viscosity of the unburned gases. The entrainment equations are used as a mathematical representation of the effects of a finite flame thickness [8]. 
- The quantities $p, T_{u}, T_{b}, m_{u}, m_{b}$, and $m_{e}$ are initialized as mentioned in $[8]$.

- Gas properties are taken from the standard GT-Power libraries [19], supplemented with data for methanol from the chemical oxidation mechanism of Li et al. [37].

- A flame propagating after spark ignition is first only wrinkled by the smallest scales of turbulence. For the simulations done in this work, a flame development multiplying factor for the turbulent entrainment velocity was used, based on work by Lipatnikov and Chomiak [27]:

$$
\frac{u_{t k}}{u_{t}}=\left(1+\frac{\tau^{\prime}}{t_{k}}\left[\exp \left(-\frac{t_{k}}{\tau^{\prime}}\right)-1\right]\right)^{1 / 2}
$$

Where $t_{k}$ is the time from ignition and the time constant $\tau^{\prime}$ is given by $0.55 \Lambda / u^{\prime}$.

- For simplicity, blowby rates and the influence of crevice volumes have been neglected.

$$
\frac{1}{\Sigma} \frac{\mathrm{d} \Sigma}{\mathrm{d} t}=\Gamma\left(u^{\prime} / u_{l}, \Lambda / \delta_{l}\right) \frac{u^{\prime}}{\Lambda}\left(\frac{\Sigma_{e q}-\Sigma}{\Sigma_{e q}-1}\right)-\frac{2}{r_{b g}}(1+\tau)(\Sigma-1) u_{l}
$$

where $\tau=\rho_{u} / \rho_{b}, r_{b g}=\left(3 V_{b} / 4 \pi\right)^{1 / 3}$ is the burnt gas mean radius and the laminar flame thickness $\delta_{l}$ is obtained from $\delta_{l}=\nu / u_{l}$. Alternatively, the flame 
thickness can be more precisely calculated using the $\delta_{l}$ correlations developed by the current authors $[20,21]$. The stretch efficiency function $\Gamma$ measures the efficiency of turbulence motions to wrinkle the flame front. The first term on the right hand side represents the flame strain caused by all turbulent structures, while the second simulates the effect of thermal expansion, which limits the flame front wrinkling by imposing positive curvature on the flame front [29]. $\Sigma_{e q}$ is the value of $\Sigma$ when equilibrium is reached between turbulence and flame front wrinkling. It is given by:

$$
\Sigma_{e q}=1+\frac{2}{u_{l}} \sqrt{\frac{C \Gamma u^{\prime 2}}{1-C^{*} /(1+\tau)}}
$$

Where proposed values for the constants are $C^{*}=0.5$ and $C=0.12$. Richard et al. [29] report that the use of a balance equation for $\Sigma$ improves the transition from laminar to turbulent combustion compared to fractal modeling approaches such as that by Bozza et al. [54].

${ }_{920}$ The stretch efficiency function $\Gamma$ is mainly a function of the integral length scale and the laminar flame thickness, and is nearly independent from the rms turbulent burning velocity $u^{\prime}[55]$. A simple formulation for $\Gamma$ is used here:

$$
\Gamma=C_{1} \frac{\Lambda}{\delta_{l}}
$$

Appendix A.3. Measurement conditions

Measurement conditions are given in Tables A.3 to A.6.

Appendix A.4. Calibration procedure

The heat transfer multipliers are calibrated as follows:

- compression: the multiplier is calibrated by matching the cylinder pressure from IVC till spark timing.

- combustion: the heat transfer multiplier during combustion is used to tweak the in-cylinder energy balance, ensuring that the cumulative energy (sum of work, internal energy and heat transfer) matches the total injected fuel energy. Note that the real heat loss during combustion can be expected to be lower than the predicted value, since the effects of blow-by and incomplete combustion are lumped into the heat transfer multiplier. 
- expansion: the multiplier is calibrated by matching the cylinder pressure during expansion.

The combustion model multipliers are calibrated using the following pro-

- Set all multipliers to 1

- Pick a few operation points with a high ignition delay and try to find a value of $C_{1}$ in order to make the ignition delay prediction acceptable (e.g. within $2^{\circ} \mathrm{ca}$ ).

- $C_{2}$ and $C_{3}$ are optimized simultaneously be minimizing the root mean square (RMS) error between measured and calculated normalized burn rate using the Response Surface Methods described in [41]. Simulations are run with values for $C_{2}$ and $C_{3}$ varying in a certain range. Then a response surface is fitted to the RMS burn rate error. If a minimum is found, the corresponding values for $C_{2}$ and $C_{3}$ are used. If not, their range is extended and the step is repeated.

- The procedure is repeated from step 2 with the new values for $C_{2}$ and $C_{3}$.

The knock prediction models were calibrated by multiplying the knock ignition delay correlation with a factor in order to get autoignition onset exactly at the measured crank angle of knock onset for a reference condition in the middle of the explored parameter space [34].

The calibration constants for the different engine models in this work are summarized in Tables A.7 to A.9. 
Table A.3: Measurement conditions: neat methanol operation on CFR engine - IT in ${ }^{\circ} \mathrm{ca}$ ATDC, $\lambda_{m}$ denotes the value for $\lambda$ calculated from the measured air and fuel mass flow rates; $\lambda_{s}$ denotes the value measured with the wide band $\lambda$ sensor. $600 \mathrm{rpm}$. TP: $0^{\circ}=$ open, $90^{\circ}=$ closed.

\begin{tabular}{|c|c|c|c|c|c|c|}
\hline $\mathrm{CR}$ & $\lambda_{m}$ & $\phi$ & $\begin{array}{c}\mathrm{TP} \\
{\left[{ }^{\circ}\right]}\end{array}$ & $\begin{array}{c}\text { IT } \\
{\left[{ }^{\circ} \mathrm{ca}\right]}\end{array}$ & $\begin{array}{c}\text { EGR } \\
{[\%]}\end{array}$ & $\lambda_{s}$ \\
\hline 9.0 & 1.00 & 1.00 & 75 & -15 & 6.1 & 0.98 \\
9.0 & 1.00 & 1.00 & 87 & -15 & 12.5 & 1.00 \\
9.0 & 1.00 & 1.00 & 75 & -5 & 6.3 & 0.98 \\
9.0 & 1.30 & 0.77 & 75 & -15 & 6.6 & 1.20 \\
8.5 & 1.15 & 0.87 & 81 & -20 & 10.0 & 1.09 \\
8.5 & 0.85 & 1.18 & 81 & -10 & 8.7 & 0.78 \\
8.5 & 1.15 & 0.87 & 69 & -10 & 5.8 & 1.08 \\
8.5 & 0.85 & 1.18 & 69 & -20 & 5.7 & 0.79 \\
9.5 & 1.15 & 0.87 & 81 & -10 & 8.5 & 1.09 \\
9.5 & 0.85 & 1.18 & 81 & -20 & 8.4 & 0.79 \\
9.5 & 1.15 & 0.87 & 69 & -20 & 5.7 & 1.09 \\
9.5 & 0.85 & 1.18 & 69 & -10 & 5.2 & 0.79 \\
9.0 & 0.70 & 1.43 & 75 & -15 & 6.2 & 0.69 \\
9.0 & 1.00 & 1.00 & 75 & -15 & 6.5 & 0.98 \\
9.0 & 1.00 & 1.00 & 75 & -25 & 6.6 & 0.97 \\
9.0 & 1.00 & 1.00 & 63 & -15 & 5.6 & 0.97 \\
7.0 & 1.00 & 1.00 & 75 & -15 & 7.8 & 0.97 \\
11.0 & 1.00 & 1.00 & 75 & -15 & 5.6 & 0.97 \\
\hline
\end{tabular}


Table A.4: Measurement conditions: neat ethanol operation on CFR engine . IT in ${ }^{\circ} \mathrm{ca}$ ATDC, $\lambda$ from $\lambda$ sensor. $600 \mathrm{rpm}$. TP: $0^{\circ}=$ open, $90^{\circ}=$ closed.

\begin{tabular}{|c|c|c|c|c|c|}
\hline CR & $\lambda$ & $\phi$ & $\begin{array}{c}\text { TP } \\
{\left[{ }^{\circ}\right]}\end{array}$ & $\begin{array}{c}\text { IT } \\
{\left[{ }^{\circ} \mathrm{ca}\right]}\end{array}$ & $\begin{array}{c}\text { EGR } \\
{[\%]}\end{array}$ \\
\hline 8.5 & 0.99 & 1.01 & 75 & -15 & 5.8 \\
8.5 & 1.00 & 1.00 & 87 & -15 & 10.2 \\
8.5 & 1.00 & 1.00 & 75 & -5 & 5.5 \\
8.5 & 1.32 & 0.76 & 75 & -15 & 6.2 \\
8.0 & 1.15 & 0.87 & 81 & -20 & 7.9 \\
8.0 & 0.86 & 1.17 & 81 & -10 & 7.0 \\
8.0 & 1.15 & 0.87 & 69 & -10 & 5.9 \\
8.0 & 0.85 & 1.18 & 69 & -20 & 5.7 \\
9.0 & 1.17 & 0.86 & 81 & -10 & 6.7 \\
9.0 & 0.86 & 1.17 & 81 & -20 & 6.6 \\
9.0 & 1.17 & 0.85 & 69 & -20 & 5.6 \\
9.0 & 0.86 & 1.16 & 69 & -10 & 5.0 \\
8.5 & 0.70 & 1.43 & 75 & -15 & 5.4 \\
8.5 & 1.01 & 0.99 & 75 & -15 & 5.8 \\
8.5 & 0.98 & 1.02 & 75 & -25 & 5.9 \\
8.5 & 1.00 & 1.00 & 63 & -15 & 5.4 \\
7.5 & 1.01 & 1.00 & 75 & -15 & 6.6 \\
6.5 & 1.00 & 1.00 & 75 & -15 & 7.5 \\
\hline
\end{tabular}


Table A.5: Measurement conditions: neat methanol operation on Audi engine . IT in ${ }^{\circ} \mathrm{ca}$ ATDC. TP: $90^{\circ}=$ open, $0^{\circ}=$ closed.

\begin{tabular}{|c|c|c|c|c|c|}
\hline $\mathrm{rpm}$ & $\lambda$ & $\phi$ & $\begin{array}{c}\mathrm{TP} \\
{\left[{ }^{\circ}\right]}\end{array}$ & $\begin{array}{c}\mathrm{IT} \\
{\left[{ }^{\circ} \mathrm{ca}\right]}\end{array}$ & $\begin{array}{c}\mathrm{CoV} \\
{[\%]}\end{array}$ \\
\hline 3010 & 0.85 & 1.18 & 65 & -15 & 2.0 \\
2497 & 1.00 & 1.00 & 50 & 0 & 8.4 \\
3008 & 0.85 & 1.18 & 65 & -5 & 6.2 \\
2503 & 1.00 & 1.00 & 80 & -10 & 7.0 \\
1991 & 1.15 & 0.87 & 35 & -5 & 12.0 \\
2500 & 1.30 & 0.77 & 50 & -10 & 46.6 \\
2500 & 0.70 & 1.43 & 50 & -10 & 2.4 \\
1993 & 0.85 & 1.18 & 35 & -5 & 2.2 \\
1998 & 1.15 & 0.87 & 65 & -5 & 11.7 \\
2009 & 1.15 & 0.87 & 65 & -15 & 6.3 \\
2001 & 0.85 & 1.18 & 65 & -5 & 2.6 \\
1993 & 1.15 & 0.87 & 35 & -15 & 6.6 \\
3002 & 1.15 & 0.87 & 35 & -15 & 6.2 \\
3008 & 1.15 & 0.87 & 65 & -5 & 23.6 \\
2999 & 0.85 & 1.18 & 35 & -5 & 2.8 \\
3011 & 1.15 & 0.87 & 65 & -15 & 13.1 \\
3005 & 0.85 & 1.18 & 35 & -15 & 1.5 \\
2505 & 1.00 & 1.00 & 50 & -10 & 4.8 \\
3004 & 1.15 & 0.87 & 35 & -5 & 13.8 \\
1994 & 0.85 & 1.18 & 35 & -15 & 1.0 \\
2499 & 1.00 & 1.00 & 50 & -10 & 4.7 \\
3515 & 1.00 & 1.00 & 50 & -10 & 9.9 \\
2496 & 1.00 & 1.00 & 50 & -10 & 4.3 \\
2502 & 1.00 & 1.00 & 50 & -10 & 4.7 \\
2506 & 1.00 & 1.00 & 20 & -10 & 3.3 \\
2504 & 1.00 & 1.00 & 50 & -20 & 2.7 \\
1500 & 1.00 & 1.00 & 50 & -10 & 3.6 \\
2003 & 0.85 & 1.18 & 65 & -15 & 0.8 \\
\hline & & & & & \\
\hline
\end{tabular}


Table A.6: Measurement conditions: neat methanol operation on Audi engine with external EGR . IT in ${ }^{\circ} \mathrm{ca}$ ATDC. TP: $90^{\circ}=$ open, $0^{\circ}=$ closed.

\begin{tabular}{|c|c|c|c|c|c|}
\hline rpm & $\lambda$ & $\phi$ & $\begin{array}{c}\text { TP } \\
{\left[{ }^{\circ}\right]}\end{array}$ & $\begin{array}{c}\text { IT } \\
{\left[{ }^{\circ} \mathrm{ca}\right]}\end{array}$ & $\begin{array}{c}\mathrm{EGR}_{\text {ext }} \\
{[\%]}\end{array}$ \\
\hline 1500 & 1.0 & 1.0 & WOT & 38 & 25.9 \\
1500 & 1.0 & 1.0 & WOT & 23 & 14.4 \\
1500 & 1.0 & 1.0 & WOT & 16 & 0.0 \\
\hline
\end{tabular}

Table A.7: Calibration constants for methanol operation on the CFR engine

\begin{tabular}{llllll}
\hline$u_{t}$ model & $C_{h t r, \text { compr }}$ & $C_{h t r, \text { comb }}$ & $C_{h t r, e x p}$ & $C_{1}$ & $C_{2}$ \\
\hline Damköhler & 1.3 & 2.8 & 0.3 & 1.0 & 1.60 \\
Zimont & 1.3 & 2.8 & 0.3 & 0.5 & 0.28 \\
Dinkelacker & 1.3 & 2.8 & 0.3 & 0.5 & 0.28 \\
Gülder & 1.3 & 2.8 & 0.3 & 0.5 & 0.28 \\
Bradley KaLe & 1.3 & 2.8 & 0.3 & 0.5 & 0.32 \\
Coherent Flame Model & 1.3 & 2.8 & 0.3 & - & 0.08 \\
\hline
\end{tabular}

Table A.8: Calibration constants for ethanol operation on the CFR engine

\begin{tabular}{llllll}
\hline$u_{t}$ model & $C_{h t r, \text { compr }}$ & $C_{h t r, \text { comb }}$ & $C_{h t r, e x p}$ & $C_{1}$ & $C_{2}$ \\
\hline Damköhler & 1.3 & 2.3 & 0.3 & 0.5 & 1.60 \\
Zimont & 1.3 & 2.3 & 0.3 & 0.5 & 0.32 \\
Zimont, Gülder $u_{l}$ & 1.3 & 2.3 & 0.3 & 0.5 & 0.25 \\
Dinkelacker & 1.3 & 2.3 & 0.3 & 0.5 & 0.29 \\
Bradley KaLe & 1.3 & 2.3 & 0.3 & 0.5 & 0.37 \\
\hline
\end{tabular}


Table A.9: Calibration constants for methanol operation on the Audi engine

\begin{tabular}{lllllll}
\hline$u_{t}$ model & $C_{h t r, \text { compr }}$ & $C_{h t r, \text { comb }}$ & $C_{h t r, \text { exp }}$ & $C_{1}$ & $C_{2}$ & $C$ \\
\hline Damköhler & 1.3 & 2.0 & 0.3 & 1.5 & 1.50 & 0. \\
Zimont & 1.3 & 2.0 & 0.3 & 1.5 & 0.38 & 0. \\
Dinkelacker & 1.3 & 2.0 & 0.3 & 1.5 & 0.45 & 1. \\
Bradley KaLe & 1.3 & 2.0 & 0.3 & 1.5 & 0.62 & 1. \\
\hline
\end{tabular}

